\title{
Allelic Frequencies of Mutations in Blood Coagulation Factor Genes (Factor V, Factor II) and Methylenetetrahydrofolate Reductase (MTHFR) in 201 Turkish Patients with Venous Thrombosis Complications
}

Nesrin Öztürk Erçelen*, Berrin Öztürk, Havva Cömert, Mustafa Diken, Meral Gültomruk, Havva Coşkun and Ayberk Akat

Bahçeşehir University Medical School, Department of Medical Genetics, Çırağan Cad. Osmanpaşa Mektebi Sok. No: 4-6 34353 Beşiktaş, Istanbul, Turkey

\begin{abstract}
Background and objectives: The objective of this study is to determine the prevalence of factor $V$ Leiden (G1691A), prothrombin (G20210A) and MTHFR (C677T) gene mutations in 201 Turkish patients who were referred to our clinic with venous thrombosis complications such as deep venous thrombosis, ischemic complications, thromboembolism and coronary artery disease. Methods: After isolation of genomic DNA from peripheral blood samples, polymerase chain reaction (PCR) and restriction fragment length polymorphism techniques were used for analysis.
\end{abstract}

Results: Among patients with venous thrombosis complications, allelic frequencies were $0.33,0.17$ and 0.04 for MTHFR (C677T), factor V Leiden (G1691A) and prothrombin (G20210A) mutations respectively.

Conclusion: Homozygosity for the MTHFR C677T mutation and/or presence of at least one copy of the A allele of the Factor V Leiden G1691A mutation was found to be associated with increased incidence of venous thrombosis complications in patients $(p<0.01)$. The combined impact of these mutations on venous thrombosis should also be taken into consideration. In our study, prothrombin (G20210A) mutation was found not to be associated with venous thrombosis complications. We also found that the prevalence of factor V Leiden (G1691A), prothrombin (G20210A) and MTHFR (C677T) gene mutations in Turkish patients with venous thrombosis are comparable to results of other studies performed in Turkish and Caucasian populations. We did not observe any significant gender dependency for the factor V Leiden (G1691A), prothrombin (G20210A) and MTHFR (C677T) gene mutations in venous thrombosis complications.

Keywords: Factor V Leiden; Prothrombin; MTHFR; Mutation; Venous thrombosis

\section{Introduction}

Thrombophilia is considered to be associated with both genetic and non-genetic factors. Acquired mutations in blood coagulation factor (Factor V, Factor II) genes and genes coding for enzymes involved in the homocysteine metabolism (MTHFR) are reported to play a role in the development of venous thrombosis. The association of mutations in these genes and others such as ACE and PON1 in the development of coronary artery disease (CAD) has also been evaluated by other groups [1-3].

Factor $\mathrm{V}$ Leiden phenotype results from a single point mutation in the Factor V gene ( $G$ to A substitution at nucleotide position 1691), which leads to APC-resistance [4]. APC-resistance is a common inherited risk factor in venous thrombosis complications such as deep venous thrombosis, thromboembolism and coronary artery disease. The relative risk in heterozygous individuals is increased sevenfold whereas an 80 -fold increase in thrombosis risk was observed in homozygous individuals [5]. The risk of venous thrombosis in patients with factor V Leiden (FVL) (G1691A) gene mutation further increases with the use of oral contraceptives [6]. Activated protein $\mathrm{C}$ resistance due to G1691A mutation in the Factor V Leiden gene is also reported to be associated with recurrent foetal losses in the second semester $[7,8]$. The prevalence of factor $\mathrm{V}$ Leiden $(\mathrm{G} 1691 \mathrm{~A})$ gene mutation varies among different populations (2-15\%) and factor V Leiden mutant allele was found to be present in about $5 \%$ of Caucasian populations $[9,10]$.

Factor II (prothrombin) gene mutation is considered to be the second most common genetic defect related to thrombosis. The prothrombin mutation ( $G$ to A substitution at nucleotide position
20210) in the 3'-untranslated region of Factor II gene is responsible for the increase in prothrombin levels which in turn increases the risk of venous thrombosis and is observed in $2 \%$ of white populations [11]. It has also been described as a risk factor for arterial thrombosis [12].

Methylenetetrahydrofolate reductase (MTHFR) is a key enzyme in folic acid metabolism and catalyses the reduction of methylenetetrahydrofolate to methyltetrahydrofolate. Methyltetrahydrofolate is required for remethylation of homocysteine to methionine. The C677T mutation in the MTHFR gene results in a two-third decrease in the activity of MTHFR and renders the enzyme labile to heat. As a result, homocysteine levels in blood and urine are elevated [13]. High level of homocysteine was found to be associated with coronary artery disease (CAD) and is an independent risk factor for cardiovascular disease [14-16]. Elevated levels of homocysteine pose an increased risk for (1) hardening of the arteries (atherosclerosis), which could eventually result in a heart attack and/or stroke, and (2) blood clots in veins, referred

${ }^{*}$ Corresponding author: Nesrin Öztürk Erçelen M.D, Bahçeşehir University Medical School, Department of Medical Genetics, Çırağan Cad. Osmanpaşa Mektebi Sok. No: 4-6 34353 Beşiktaş, Istanbul, Turkey, Tel: +90 2124442864 Fax: +90 21238100 20; E-mail: nesrinercelen@gmail.com

Received August 16, 2013; Accepted December 10, 2013; Published December 17,2013

Citation: Erçelen NÖ, Öztürk B, Cömert H, Diken M, Gültomruk M, et al. (2014) Allelic Frequencies of Mutations in Blood Coagulation Factor Genes (Factor V, Factor II) and Methylenetetrahydrofolate Reductase (MTHFR) in 201 Turkish Patients with Venous Thrombosis Complications. J Mol Genet Med 7: 93 doi: 10.4172/1747-0862.1000093

Copyright: ( 2014 Erçelen NÖ, et al. This is an open-access article distributed under the terms of the Creative Commons Attribution License, which permits unrestricted use, distribution, and reproduction in any medium, provided the original author and source are credited 
Citation: Erçelen NÖ, Öztürk B, Cömert H, Diken M, Gültomruk M, et al. (2014) Allelic Frequencies of Mutations in Blood Coagulation Factor Genes (Factor V, Factor II) and Methylenetetrahydrofolate Reductase (MTHFR) in 201 Turkish Patients with Venous Thrombosis Complications. J Mol Genet Med 7: 93 doi: 10.4172/1747-0862.1000093

to as venous thrombosis. C677T mutation is estimated to be observed in approximately $30-40 \%$ of the world population $[13,17]$.

In this study, the prevalence of factor $\mathrm{V}$ Leiden (G1691A), prothrombin (G20210A) and MTHFR (C677T) gene mutations were investigated in 201 Turkish patients who were referred to our clinic with venous thrombosis complications such as deep venous thrombosis, ischemic complications, thromboembolism and coronary artery disease. Our control study group consisted of 98 patients who had no venous thrombosis complications.

\section{Materials and Methods}

\section{Study group}

We compared the allelic frequencies of MTHFR, factor V Leiden and prothrombin gene mutations among 201 patients that were referred to our clinic with venous thrombosis complications such as deep venous thrombosis, ischemic complications, thromboembolism and coronary artery disease with a control group of 98 healthy individuals who had no venous thrombosis complications in their previous medical records. The patients' diagnosis was confirmed in cardiovascular, neurology and other clinics of our and other hospitals. Limited demographic information was available. Table 1 represents information about the number of individuals, male /female distribution and mean ages of our study and control groups.

Each individual was informed about the test procedure before blood was drawn and a written consent form was obtained.

\section{Extraction of DNA for mutation analysis}

Venous blood was drawn into tubes containing EDTA. Human genomic DNA was isolated from peripheral blood samples by using the PUREGENETM DNA Isolation Kit (GENTRA Systems).

\section{Detection of FVL (G1691A), prothrombin (G20210A) and MTHFR (C677T) mutations}

Polymerase chain reaction (PCR) was performed to amplify genomic DNA. Primers and PCR conditions were designed as mentioned above (Yilmaz et al. [18,19] and Conroy et al. [20]). PCR products were cut with Mnl I, Hinf I and Hind III restriction endonucleases to detect mutations in Factor V Leiden, MTHFR and Prothrombin genes, respectively. RE digestion was followed by agarose gel electrophoresis (AGE) and band patterns on 2\% agarose gel (Metaphor Agarose, Cambrex Bio Sciences) were observed by UV transilluminator (Biolab UV Pro Image Analyser).

\section{Data analysis}

Genotype and allele frequency data from patient and control groups were statistically analysed by Chi square test for independence using $3 \times 2$ and $2 \times 2$ contingency tables, respectively. Tests for association

\begin{tabular}{|c|c|c|}
\hline & Study Group & Control Group \\
\hline $\mathrm{n}$ & 201 & 98 \\
\hline $\mathrm{n}(\mathrm{F})$ & 114 & 50 \\
\hline $\mathrm{n}(\mathrm{M})$ & 87 & 48 \\
\hline Mean Age & & \\
\hline Female & $37.62( \pm 17)$ & $32.2( \pm 10.7)$ \\
\hline Male & $41.18( \pm 17)$ & $29.7( \pm 11.7)$ \\
\hline
\end{tabular}

Nesrin Ercelen M.D., Ph.D.

Table 1: Represents information about the number of individuals, male /female distribution and mean ages of our study and control groups. (allele frequency difference, heterozygous, homozygous and allele positivity) were done by employing an online statistics tool (http://ihg. gsf.de). Interpretation of statistical data was performed as previously described [21], p values smaller than $0.05(\mathrm{p}<0.05)$ were considered statistically significant.

\section{Results}

We have screened the most common mutations in blood coagulation factor genes (Factor V, Factor II) and Methylenetetrahydrofolate Reductase (MTHFR) gene in 201 Turkish patients who were referred to our clinic with venous thrombosis complications such as deep venous thrombosis, ischemic complications, thromboembolism and coronary artery disease (study group) and 98 healthy individuals with no venous thrombosis complications in their previous medical records (control group).

Study Group: 201 patients that were referred to our department with venous thrombosis complications such as deep venous thrombosis, ischemic complications, thromboembolism and coronary artery disease. The number of male patients was 87 ; the number of female patients was 114 . The average age of male patients was $41.18( \pm$ 17). The average age of female patients was $37.62( \pm 17)$. No significant age difference between genders ( $\mathrm{p}>0.05)$ was observed.

Control study group: 98 patients who had no venous thrombosis complications. The number of male patients was 48; the number of female patients was 50 . The average age of the control group was $31( \pm$ 11.2). The average age of male patients in the control group was 29.7 $( \pm 11.7)$. The average age of female patients in the control group was $32.2( \pm 10.7)$

\section{Prevalence of mutations in 201 patients with venous thrombosis complications}

Molecular genetic analysis of factor V Leiden (G1691A), prothrombin (G20210A) and MTHFR (C677T) gene mutations of 201 patients revealed that MTHFR (C677T) is the most frequent mutation with an allelic frequency of 0.33 (41.8\% CT, 12.4\% TT) Among our control group, the allelic frequency of the MTHFR mutation was 0.23 (46.9\% CT, 0\% TT) (Figure 1 and Table 2).

Factor V Leiden (G1691A) mutation was the second most common

\section{Comparison of Allelic Frequencies between our Study Group and Control Group}

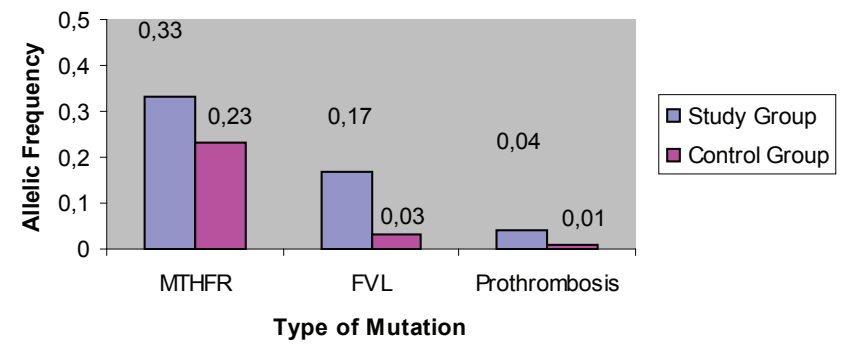

NesrinErcelen M.D., Ph.D.

Study Group: 201 Turkish patients who were referred to our clinic with venous thrombosis complications such as deep venous thrombosis, ischemic complications, thromboembolism and coronary artery disease.

Control Group: 98 healthy individuals with no venous thrombosis complications.

Figure 1: Comparison of Allelic Frequencies of MTHFR, FVL and prothrombin Mutations between our Study Group and Control Group. 
Citation: Erçelen NÖ, Öztürk B, Cömert H, Diken M, Gültomruk M, et al. (2014) Allelic Frequencies of Mutations in Blood Coagulation Factor Genes (Factor V, Factor II) and Methylenetetrahydrofolate Reductase (MTHFR) in 201 Turkish Patients with Venous Thrombosis Complications. J Mol Genet Med 7: 93 doi: 10.4172/1747-0862.1000093

mutation with an allelic frequency of 0.17 (29.4\% GA, 2\% AA). Among our control group, the allelic frequency of the factor $\mathrm{V}$ Leiden mutation was 0.05 (10.2\% GA, 0\% AA) (Figure 1 and Table 2).

The prevalence of the prothrombin (G20210A) mutation was rather low with an allelic frequency of 0.04 (8\% GA, 0\% AA). Among our control group, the allelic frequency of the prothrombin mutation was 0.01 (2\% GA, 0\% AA) (Figure 1 and Table 2).

Chi square test for independence using $3 \times 2$ contingency tables in 201 Turkish patients with venous thrombosis complications and our control group of 98 individuals revealed that MTHFR (C677T) and FVL (G1691A) mutations result in significantly different distributions of genotypes between patient and control groups $(\mathrm{p}<0.05)$. No significant difference in the distribution of genotypes was observed between patient and control groups for the prothrombin (G20210A) mutation ( $p>0.05)$. The allele frequencies of MTHFR (C677T) and prothrombin (G20210A) mutations did not differ significantly between patient and control groups $(p>0.05)$. However, Chi square test for independence using $2 \times 2$ contingency tables provided reliable evidence of the existence of a significant difference for the FVL (G1691A) mutation between patient and control groups $(\mathrm{p}<0.01)$. T allele of the MTHFR gene in the homozygous state provided increased risk for venous thrombosis complications ( $\mathrm{p}<0.01$, homozygous test for association). Allele positivity test also revealed the association of A allele of Factor $\mathrm{V}$ gene with complications in this study group ( $<<0.01$, OR: 4.02).

\section{Prevalence of mutations among male and female patients}

We also compared the allelic frequencies of factor $\mathrm{V}$ Leiden (G1691A), prothrombin (G20210A) and MTHFR (C677T) gene mutations among male and female patients with venous thrombosis complications.

The allelic frequency of the MTHFR (C677T) mutation for female patients was $0.36(50 \% \mathrm{CT}, 10.3 \% \mathrm{TT})$. The allelic frequency for male patients was 0.38 (36\% CT, $14 \%$ TT). Our analysis revealed that there was no significant difference in the prevalence of the MTHFR (C677T) mutation between male and female patients $(\mathrm{p}>0.05)$ (Table 3$)$.

The allelic frequency of the factor $\mathrm{V}$ Leiden mutation in female patients was $0.14(23.6 \% \mathrm{GA}, 1.8 \% \mathrm{AA})$. The allelic frequency of the factor V Leiden mutation in male patients was 0.21 (36.8\% GA, $2.3 \%$ $\mathrm{AA})$. Our analysis revealed that there is no significant difference in the

\begin{tabular}{|c|c|c|c|c|}
\hline MTHFR (C677T) & CC & CT & TT* $^{*}$ & Allelic Frequency \\
\hline $\mathrm{n}(\%)$ Patients & $92(45.8)$ & $84(41.8)$ & $25(12.4)$ & 0.33 \\
\hline $\mathrm{n}(\%)$ Control & $52(53.1)$ & $46(46.9)$ & $0(0)$ & 0.23 \\
\hline Factor V Leiden (G1691A) & GG & GAФ & AA & Allelic Frequency \\
\hline $\mathrm{n}(\%)$ Patients & $138(68)$ & $59(29.4)$ & $4(2)$ & 0.17 \\
\hline $\mathrm{n}(\%)$ Control & $88(89.8)$ & $10(10.2)$ & $0(0)$ & 0.05 \\
\hline Prothrombin (G20210A) & GG & GA & AA & Allelic Frequency \\
\hline $\mathrm{n}(\%)$ Patients & $185(92)$ & $16(8)$ & $0(0)$ & 0.04 \\
\hline $\mathrm{n}(\%)$ Control & $96(98)$ & $2(2)$ & $0(0)$ & 0.01 \\
\hline
\end{tabular}

Table 2: Prevalence of factor $V$ Leiden (G1691A), prothrombin (G20210A) and MTHFR (C677T) gene mutations in 201 Turkish patients with venousthrombosis complications and in 98 individuals with no venous thrombosis complications.

\begin{tabular}{|c|c|c|c|c|}
\hline MTHFR (C677T) & CC & CT $^{*}$ & TT & Allelic Frequency \\
\hline Female, $\mathrm{n}(\%)$ & $45(39.7)$ & $57(50)$ & $12(10.3)$ & 0.36 \\
\hline Male, $\mathrm{n}(\%)$ & $44(50)$ & $31(36)$ & $12(14)$ & 0.38 \\
\hline
\end{tabular}

Table 3: Prevalence of the MTHFR (C677T) mutationamong male and female patients with venous thrombosis complications. prevalence of the factor $\mathrm{V}$ Leiden (G1691A) mutation between male and female patients $(\mathrm{p}>0.05)$ (Table 4$)$.

The allelic frequency of the prothrombin (G20210A) gene mutation among female patients was 0.03 (6.1\% GA, 0\% AA). The allelic frequency of the prothrombin (G20210A) gene mutation among male patients was $0.05(9.2 \% \mathrm{GA}, 0 \% \mathrm{AA})$. Our analysis revealed that there is no significant difference in the prevalence of the prothrombin $(\mathrm{G} 20210 \mathrm{~A})$ gene mutation between male and female patients $(\mathrm{p}>0.05)$ (Table 5).

\section{Discussion}

We analysed the prevalence of three thrombophilic gene mutations: MTHFR (C677T), factor V Leiden (G1691A) and prothrombin (G20210A) in a total of 201 patients that were referred to our genetics department with venous thrombosis complications such as deep venous thrombosis, ischemic complications, thromboembolism and coronary artery disease.

Our control group consisted of 98 patients that had no venous thrombosis complications.

Our analysis revealed that MTHFR (C677T) mutation is the most prevalent mutation among patients with venous thrombosis complications. MTHRF showed an allelic frequency of $0.33(41.8 \%$ CT, $12.4 \%$ TT) (Table 2). The prevalence of the MTHFR mutation among our control group was $46.9 \%$ (allelic frequency: 0.23 ). This is in accordance with the results of the study of Conroy et al. who found that the prevalence of the MTHFR mutation was $47.4 \%$ among randomly selected Caucasian New York Residents [20]. Another study by Frosst et al. shows that the MTHFR (C677T) substitution occurs at a frequency of approximately $38 \%$ of unselected chromosomes [13].

Meta-analysis demonstrated that the 677TT genotype was associated with a $20 \%$ increased risk of venous thrombosis [22]. The prevalence among Caucasians of Northern European descent with the 677TT genotype for MTHFR has been reported to be about $10-12 \%$. They present with $25 \%$ higher homocysteine levels than those with the 677CC genotype. The effect of the MTHFR 677TT genotype on homocysteine levels varies according to folate or riboflavin status [23]. Individuals with the MTHFR 677 TT genotype have a 16\% higher odds of coronary artery disease compared with individuals with the CC genotype secondary to impaired folate metabolism, resulting in high homocysteine concentrations, plays a causal role in the occurrence of coronary artery disease. The clinical value of screening for MTHFR $677 \mathrm{C} \rightarrow \mathrm{T}$ genotype in the general population for prediction of coronary artery disease risk is yet to be sought [24].

FVL mutation was the second most common mutation with an allelic frequency of 0.17 (29.4\% GA, 2\% AA) (Table 2). This also correlates with data from other studies which indicate that factor $\mathrm{V}$

\begin{tabular}{|c|c|c|c|c|}
\hline Factor V Leiden (G1691A) & GG & GA $^{*}$ & AA & Allelic Frequency \\
\hline Female, $\mathrm{n}(\%)$ & $85(74.6)$ & $27(23.6)$ & $2(1.8)$ & 0.14 \\
\hline Male, $\mathrm{n}(\%)$ & $53(60.9)$ & $32(36.8)$ & $2(2.3)$ & 0.21 \\
\hline
\end{tabular}

Table 4: Prevalence of the factor $V$ Leiden (G1691A) mutationamong male and female patients with venous thrombosis complications.

\begin{tabular}{|c|c|c|c|c|}
\hline Prothrombin(G20210A) & GG & GA $^{*}$ & AA & Allelic Frequency \\
\hline Female, $\mathrm{n}(\%)$ & $107(93.9)$ & $7(6.1)$ & $0(0)$ & 0.03 \\
\hline Male, $\mathrm{n}(\%)$ & $79(90.8)$ & $8(9.2)$ & $0(0)$ & 0.05 \\
\hline
\end{tabular}

Table 5: Prevalence of the prothrombin (G20210A)gene mutation among male and female patients with venous thrombosis complications. 
Citation: Erçelen NÖ, Öztürk B, Cömert H, Diken M, Gültomruk M, et al. (2014) Allelic Frequencies of Mutations in Blood Coagulation Factor Genes (Factor V, Factor II) and Methylenetetrahydrofolate Reductase (MTHFR) in 201 Turkish Patients with Venous Thrombosis Complications. J Mol Genet Med 7: 93 doi: 10.4172/1747-0862.1000093

Leiden mutation (G1691A) occurs in $20-50 \%$ of patients with a family history of thrombosis [1]. FVL heterozygotes have seven times higher risk of thrombosis than in general population [1]. The allelic frequency for the FVL mutation among our control group was 0.05 (10.2\% GA, $0 \%$ AA). This also correlates with the study of De Stefano et al. who found that factor $\mathrm{V}$ Leiden mutant allele is present in about $5 \%$ of Caucasian populations [10]. Whether FVL influences the risk of arterial disease has not been established yet. Several studies are suggestive of an association with coronary artery disease in combination with other major cardiovascular risk factors while others failed to show any relationship.

The prevalence of the prothrombin (G20210A) mutation was rather low compared to the prevalence of MTHFR and FVL mutations. $8 \%$ of the patients with venous thrombosis complications were heterozygous for the prothrombin mutation while no patient was homozygous for the mutation (allelic frequency: 0.04 ) (Table 2). $2 \%$ of the individuals tested in our control group were heterozygous for the prothrombin mutation. Our results are in accordance with the results of Ayyildiz et al. [21] who found that the prothrombin (G20210A) gene mutation occurs at a mutation rate of $6.5 \%$ in Turkish venous thrombosis patients. Ayyildiz et al. also found that prothrombin (G20210A) gene mutation occurs at a mutation rate of $1.2 \%$ in healthy individuals from the southeast of Turkey [21].

Prothrombin G20210A mutation is a weak risk factor for venous thrombosis in combination with other transient or inherited risk factors. In particular, homozygous carriers are at increased risk of venous thromboembolism. It is unlikely that the prothrombin mutation plays a major role in the cause of other arterial thrombotic disease, with the exception of myocardial infarction, or pregnancyrelated complications [25]. However, studies that attempt to establish the risk for coronary artery disease have yielded conflicting results [26].

In our study, homozygosity for the MTHFR C677T mutation and/or presence of at least one copy of the A allele of the Factor V Leiden G1691A mutation was found to be associated with increased incidence of venous thrombosis complications in patients $(\mathrm{p}<0.01)$. The combined impact of these mutations on venous thrombolism should also be taken into consideration. In our study, prothrombin (G20210A) mutation was not found to be associated with venous thrombolism complications.

\section{Comparison of the prevalence of thrombophilic mutations among male and female patients with venous thrombosis complications}

Comparing the occurrence of these three thrombophilic mutations among female and male patients with venous thrombosis complications revealed that there is no significant difference in the prevalence of these mutations between male and female patients ( $p>0.05)$. The allelic frequency of the MTHFR (C677T) mutation among female patients is 0.36 . The allelic frequency among male patients is 0.38 (Table 3 ). Conroy et al. have also not observed any gender bias in homozygosity for the MTHFR (C677T) mutation [20]. The allelic frequency of the factor $\mathrm{V}$ Leiden mutation for male patients is 0.21 . The allelic frequency for female patients is 0.14 (Table 4). The allelic frequency of the prothrombin mutation was found to be 0.03 among female patients and 0.05 among male patients (Table 5).

\section{Conclusion}

Homozygosity for the MTHFR C677T mutation and/or presence of at least one copy of the A allele of the Factor V Leiden G1691A mutation were found to be associated with increased incidence of venous thrombosis complications in patients $(\mathrm{p}<0.01)$. The combined impact of these mutations on venous thrombosis should also be taken into consideration.

In our study, prothrombin (G20210A) mutation was not found to be associated with venous thrombosis complications.

We also found that the prevalence of factor V Leiden (G1691A), prothrombin (G20210A) and MTHFR (C677T) gene mutations in Turkish patients with venous thrombosis complications were comparable to the results of other studies performed in Turkish and Caucasian populations. We also did not observe any significant gender dependency for the factor V Leiden (G1691A), prothrombin (G20210A) and MTHFR (C677T) gene mutations.

\section{References}

1. Almawi WY, Ameen G, Tamim H, Finan RR, Irani-Hakime N (2004) Factor V $\mathrm{G} 1691 \mathrm{~A}$, prothrombin $\mathrm{G} 20210 \mathrm{~A}$, and methylenetetrahydrofolate reductase [MTHFR] C677T gene polymorphism in angiographically documented coronary artery disease. J Thromb Thrombolysis 17: 199-205.

2. Seckin D, Ilhan N, Ilhan N, Ilkay E (2005) ACE gene polymorphism is associated with the extent of coronary atherosclerosis. Adv In Mol Med 1: 87-91.

3. Agachan B, Isbir CS, Ergen HA, Yilmaz H, Yaylim H, et al. (2005) No Association Between Paraoxonase 192 And 55 Polymorphism And Increasing Risk Of Oronary Artery Disease In Turkish Patients. Adv In Mol Med 1: 92-96.

4. Bertina RM, Koeleman BP, Koster T, Rosendaal FR, Dirven RJ, et al. (1994) Mutation in blood coagulation factor $\mathrm{V}$ associated with resistance to activated protein C. Nature 369: 64-67.

5. Rosendaal FR, Koster T, Vandenbroucke JP, Reitsma PH (1995) High risk of thrombosis in patients homozygous for factor $\mathrm{V}$ Leiden (activated protein $\mathrm{C}$ resistance) Blood 85: 1504-1508.

6. Sidney S, Petitti DB, Soff GA, Cundiff DL, Tolan KK, et al. (2004) Venous thromboembolic disease in users of low-estrogen combined estrogen-progestin oral contraceptives. Contraception 70: 3-10.

7. Brenner B, Mandel H, Lanir N, Younis J, Rothbart H, et al. (1997) Activated protein $\mathrm{C}$ resistance can be associated with recurrent fetal loss. $\mathrm{Br} \mathrm{J}$ Haematol 97: 551-554.

8. Foka ZJ, Lambropoulos AF, Saravelos H, Karas GB, Karavida A, et al (2000) Factor V leiden and prothrombin G20210A mutations, but not methylenetetrahydrofolate reductase $\mathrm{C} 677 \mathrm{~T}$, are associated with recurrent miscarriages. Hum Reprod 15: 458-462.

9. Dahlbäck B (2000) Blood coagulation. Lancet 355: 1627-1632.

10. De Stefano V, Chiusolo P, Paciaroni K, Leone G (1998) Epidemiology of factor $\checkmark$ Leiden: clinical implications. Semin Thromb Hemost 24: 367-379.

11. Poort SR, Rosendaal FR, Reitsma PH, Bertina RM (1996) A common genetic variation in the $3^{\prime}$-untranslated region of the prothrombin gene is associated with elevated plasma prothrombin levels and an increase in venous thrombosis. Blood 88: 3698-3703.

12. De Stefano V, Chiusolo P, Paciaroni K, Casorelli I, Rossi E, et al. (1998) Prothrombin G20210A mutant genotype is a risk factor for cerebrovascular ischemic disease in young patients. Blood 91: 3562-3565.

13. Frosst P, Blom HJ, Milos R, Goyette P, Sheppard CA, et al. (1995) A candidate genetic risk factor for vascular disease: a common mutation in methylenetetrahydrofolate reductase. Nat Genet 10: 111-113.

14. Donnelly JG, Rock GA (1999) Genetic determinants of heritable venous thrombosis: genotyping methods for factor V(Leiden)A1691G methylenetetrahydrofolate reductase C677T, prothrombin G20210A mutation, and algorithms for venous thrombosis investigations. Clin Biochem 32: 223228.

15. Boushey CJ, Beresford SA, Omenn GS, Motulsky AG (1995) A quantitative assessment of plasma homocysteine as a risk factor for vascular disease. Probable benefits of increasing folic acid intakes. JAMA 274: 1049-1057.

16. Kluijtmans LA, van den Heuvel LP, Boers GH, Frosst P, Stevens EM, et al. (1996) Molecular genetic analysis in mild hyperhomocysteinemia: a common 
Citation: Erçelen NÖ, Öztürk B, Cömert H, Diken M, Gültomruk M, et al. (2014) Allelic Frequencies of Mutations in Blood Coagulation Factor Genes (Factor V, Factor II) and Methylenetetrahydrofolate Reductase (MTHFR) in 201 Turkish Patients with Venous Thrombosis Complications. J Mol Genet Med 7: 93 doi: 10.4172/1747-0862.1000093

Page 5 of 5

mutation in the methylenetetrahydrofolate reductase gene is a genetic risk factor for cardiovascular disease. Am J Hum Genet 58: 35-41.

17. Schneider JA, Rees DC, Liu YT, Clegg JB (1998) Worldwide distribution of a common methylenetetrahydrofolate reductase mutation. Am J Hum Genet 62 : 1258-1260.

18. Yilmaz S, Bayan K, Tüzün Y, Batun S, Altintaş A (2006) A comprehensive analysis of 12 thrombophilic mutations and related parameters in patients with inflammatory bowel disease: data from Turkey. J Thromb Thrombolysis 22: 205-212.

19. Yilmaz S, Oren H, Irken G, Türker M, Yilmaz E, et al. (2005) Cerebral venous thrombosis in a patient with Evans syndrome: a rare association. Ann Hematol 84: 124-126.

20. Conroy JM, Triverdi G, Sovd T, Caggana M (2000) The Allele Frequency Of Mutations In Four Genes That Confer Enhanced Susceptibility To Venous Thromboembolism In An Unselected Group Of New York State Newborns. Thromb Res 99: 317-324.

21. Ayyildiz O, Kalkanli S, Batun S, Aybak M, Isikdogan A, et al. (2004) Prothrombin G20210A gene mutation with LightCycler polymerase chain reaction in venous thrombosis and healthy population in the southeast of Turkey. Heart Vessels 19: 164-166.

22. Klerk M, Verhoef P, Clarke R, Blom HJ, Kok FJ, et al. (2002) MTHFR 677C-->T polymorphism and risk of coronary heart disease: a meta-analysis. JAMA 288: 2023-2031.

23. Vinukonda G (2008) Plasma Homocysteine and Methylenetetrahydrofolate Reductase Gene Polymorphism in Human Health and Disease: An Update. Int J Hum Genet 8: 171-179.

24. Den Heijer M, Lewington S, Clarke R (2005) Homocysteine, MTHFR and risk of venous thrombosis: a meta-analysis of published epidemiological studies. J Thromb Haemost 3: 292-299.

25. Bank I, Libourel EJ, Middeldorp S, Van Pampus EC, Koopman MM, et al. (2004) Prothrombin 20210A mutation: a mild risk factor for venous thromboembolism but not for arterial thrombotic disease and pregnancy-related complications in a family study. Arch Intern Med 164: 1932-1937.

26. Coulet F, Godard V, Verdy E, Soubrier F (2000) Lack of association of the prothrombin gene variant G20210A with myocardial infarction in Caucasian males. Thromb Haemost 83: 796-797. 